\title{
Social and Psychological Provisions for Actualization of the Professional Self-identity of Teenagers with Disabilities in Conditions of the Inclusive Education
}

\author{
Tatyana Ivanovna Bonkaloํㅜ, Anna Igorevna Rybakova ${ }^{1}$, \\ Sergey Vasilievich Bonkalo ${ }^{1}$, Natalia Vladimirovna Belyakova ${ }^{1}$ \\ and Irina Venidiktovna Gorohova ${ }^{2}$
}

${ }^{1}$ Russian State Social University, 4,1, V.Pika, Moscow, 129226, Russia.

${ }^{2}$ Moscow State Regional Socio-Humanitarian Institute,Bld. 30, Green Str., Kolomna, 140410, Russia.

DOI: http://dx.doi.org/10.13005/bbra/1932

(Received: 10 August 2015; accepted: 20 September 2015)

\begin{abstract}
This article is dedicated to one of the actual practice-significant challenges of the improvement of system of professional orientation work with the teenagers studying in the conditions of inclusive education. The authors substantiate the relevance of the problem under question, analyze the level of its development in the world science and practice, and determine the program of the research. The article presents the results of empirical studies of professional self-identity of the teenagers with disabilities in Russia. The authors define the psychological conditions for increasing of the efficiency of professional orientation activities of the school psychological service.
\end{abstract}

Key words: professional self-identity, professional orientation, teenagers with disabilities and invalidity, interpersonal relationship, inclusive education.

\section{Problem definition}

The problem of realization of rights of the people with disabilities and their involvement into all sectors of life has become a relevant and widely discussed tendency in the modern society. These people form a substantial part of Russian population: the overall number of people with disabilities registered in the system of Pension Fund of RF in 2011 has amounted to 13209000 people, which means 90 of each 1000 people of population of Russia (Rosstat, 2011). Among them 541000 people have not reached 18 years old (Russian statistics annual. Statistics collection,

\footnotetext{
* To whom all correspondence should be addressed.
}

2011). All these people have their special needs, and satisfaction of these needs is being the important purpose of the social policy. This is why the study of psychological aspects of these processes has been objectively determined by the current needs of the society development.

At the moment the problem of professional self-identification of the disabled persons has become more relevant. Personal and professional self-identification in early youth, which coincides with the high-school period, is the key stage in the individual's life. Thus, to a large extent all future depends on the intelligent and adequate choice that would be made during this period. Social situation of the development in the early youth is the border line of the independent life. The main measure for life horizon would 
become the future, with this not only the eventual result would have the importance, but also the ways and the means of its achievement. This is the age when an individual solves the issue of his or her formation as a subject of one's own development (Shapovalenko,2012), constitutes the psychological readiness for self-identity personal as well as the professional one (Dubrovina, 2009) which is the expanded in time process. That is why I.V. Shapovalenko defines the preliminary self-identity, and creation of life plans as the central psychological new formation of the youth period (Shapovalenko,2012).

The youth period activates the search of personal identity, the construction of the perspective of life, development of the self-identity and the person itself, elaboration of the system of values. The world outlook and the generalized attitude towards life are being created, they actualize the problem of the meaning of life in general and the meaning of one's personal life (Shapovalenko,2012). Disability, as the complex of psychological and social determinants, provides the specific character to the process of self-identity of high-school students. Russian psychology (as well as pedagogy and sociology) has not studied this specifics until now; however, there is the number of researches on related problematic outside this context, which has allowed us basing this study on the Russian and foreign experience of investigations on the psychology of the disabled people and professional and personal self-identity of youth.

\section{The level of development of the problem under question}

Modern psychological science features many approaches to the understanding of the personal and professional self-identity, the issue has been studied by many: E. A. Klimov, D. A. Leontiev, A. V. Bodrov, E.I. Golovakha, N.S. Priazhnikov, N.V. Samoukina, V.F. Safin, A.V. Mudrik, I.S. Kon, L.M. Karnozova, T.V. Kudriavtsev, G.S. Nikiforov, V.L. Ossovsky, Y.P. Povarenkov, Y.A. Repetsky, I.N. Semenov, P.A. Shavir, V.Y. Shegurova, E.V. Shelobanova.

N.S. Priazhnikov and I.S. Kon underline that the personal and professional self-identities are being inextricably connected (Priazhnikov, 1996) with this the professional self-identity forms the important part of the personal one, and however, it goes beyond it (Kon, 1999).

A theoretical analysis of the literature allowed us to formulate the author's view on the professional self-identification as the concretization and projection into the future of personal self-identification, the latter featuring such key components as the hierarchy of values and the meaning of life.

The transmission to the youth period is featured by the start of the establishing of a person as the subject of one's own development, and the leading activity during the youth period shall be the professional self-identity which should be developing on the basis of the personal one, and the educational and professional activities as the practical realization of the results of selfidentification.

Modern psychology has changed lately the paradigm of professional orientation as the activity of psychologists and teachers directed to the optant as object, to the paradigm of professional self-identification, where the leading role shall be given to the optant itself, and the specialists' role shall consist in the activation and support of the proper activity of a self-identifying person.

The relevance of the conducted study is also due to the existing number of different attitude trends towards people with disabilities, which create the specific conditions for their personal and professional self-identity in the high-school age.

On the one hand, different approaches to social work and social support are being developed and approbated. A lot of effort has been directed to include these people into all sectors of social life and to overcome the environmental and social barriers to learning and employment which cause the segregation of the disabled people.

On the other hand, however, despite a number of favorable tendencies, the situation of people with disabilities is still inadequate. One can evidence the educational and working discrimination, the failure of social security and a lot of other obvious occurrences that the disabled people would face regularly and which they usually would point out as the causes of most difficulties in their lives.

Apart from the objective restrictions due to the disability, these individuals would also face a large range of the social and psychological 
factors that would influence them subjectively. To define the complex of these occurrences we shall introduce such term as the "social invalidization". It consists of the special attitude towards the disabled people, their segregation among the other people, attributing them (beyond the objective difficulties) with the number of additional "defects", underestimation of their possibilities, infantilization. Oftenly this series of social stereotypes would be actively internalized by the disabled people themselves, who therefore find themselves prisoners of the social role they are forced to. It may lead to the inadequate personal and professional self-identification, especially among the high-school students who are very susceptible to social stereotypes.

In connection with this the scientists have been within many years developing the social and psychological conditions for integration of the children with disabilities into the society (Zajtseva, 1998). The concept of "human dignity" of children with disabilities who are capable of selfdevelopment, self-improvement, self-actualization (Astapov, 1998, Lebedinskaya and Nikolskaya, 1991 etc.). Many Russian and foreign researchers (Bonkalo and Tsigankova, 2015; Ekzhanova and Reznikova, 2008; Staroverova, 2011; Malofeev, 2005 et al) consider the inclusive education of children with deviations in development together with their healthy age mates as the naturally determined stage of the development of the whole system of special education.

Modern science describes the most efficient forms of integration (Bonkalo, 2011; Kotova, 2009; Ufimtseva, 2005; Tolstova and Arlanova, 2007 et al), analyzes the factors and processes of social and psychological adaptation of children with disabilities (Astakhov, 1999; Andreeva, 1996 et al), develop the content and the trend of psychological assistance to children with disabilities (Konopleva and Leschinskaya, 2003; Rozhkov and Bajborodova, 2003 etc.).

The inclusive education is aimed to overcome the social invalidization and segregation of people with disabilities at the stage of education in schools and technical colleges (The Law of the city of Moscow «About the education of persons with disabilities in the city of Moscow», 2010). The specifics of the inclusive education consists in the creation of special conditions for the co- education and guidance, including the organization of collaborative classes, leisure time, various types of additional education, with or without disabilities (Staroverova, 2011).

The scientific importance and the poor development of this problematic in the modern psychology has been the contradiction that we aimed to reconcile in this study.

\section{Methodology}

In connection with the significance of this problem the complex research has been undertaken, the participants were the 48 high-school students with disabilities (experimental group) and the 48 high-school students without any deviations in mental development (control group) of the inclusive general education schools.

To define the motivation in choosing of the profession by the high-school students there was used the methodology "The motives for the choice of profession" allowing to determinate why a certain profession had been chosen and envisage the level of success of its acquisition by an optant, the diligence and dedication to it and sustainability of an interest; as well as the "Questionnaire for revelation of readiness of school students for the choice of profession” (V.B. Uspensky) and the methodology «Readiness for the choice of profession» (adapted by A.P. Chernyavskaya) aimed to determination of level of freedom and independency in the choice of the profession, which is the indicator of the level of activation of professional self-identity of a school student.

Since the theoretical analysis has proven the definitive influence of the peculiarities of relationships within the inclusive school collective, there was conducted the second series of the empiric research for revelation of such peculiarities. Firstly, three experimental groups were formed: EG1- children of 9 to 15 y.o. with the diagnosed early children autism, EG2 - 15 teenagers with infantile cerebral paralysis complicated by the hearing loss of the I or II stage; and the EG3 consisting of 12 hard-hearing children 9 to 15 y.o. All children were utterly integrated into the educational process of the mass secondary school. Also, among the participants of the research there were also children with mental retardation of cerebral-organic and somatogenic nature who were studying in the correction and development classes functioning on the base of the mass schools. 
A complex of methodics were aimed to: 1 ) define the peculiarities of the development of the integrated school collective; 2) psycho-diagnostic methodics aimed to reveal the psychological factors that would determine the character of intrapersonal collaboration: «Diagnostics of emotional barriers in the intrapersonal communication» (V.V. Boiko), the questionnaire «Research on the level of the emphatic tendencies», methodology «Evaluation of the capacity of a pedagogue to the empathy», «Kettle's test» children adapted version, «Methodology for diagnostics of the development of reflexivity» (questionnaire of Karpov A.V.), methodic «Selfevaluation and the level of pretensions» T.V. Dembo - S.Y. Rubinstein in modification by A.M. Prikhozhan; 3) methodologies allowing the study of the peculiarities of relations within the system «teacher - parent»: "Satisfaction with the relationship», «Methodic for definition of the parent's position in collaboration with the teacher», «Methodic for definition of the teacher's position in cooperation with the parents of the students» (T.I. Bonkalo); 4) a complex of methodics aimed to define the peculiarities of relationships between children and parents: "The test on parent's attitude» (ÎĐÎ) A.Y. Varga, V.V. Stolin), methodic «Evaluation of parent's aims and reactions» (PARI), methodic «Emotional rejection of child in the family» (T.I. Bonkalo).

\section{RESULTS}

The results of the research of psychological peculiarities of professional self-identification of the teenagers with disabilities in conditions of the inclusive education. (Ilina et al., 2015)

During the pilot study there was made a conclusion that the problem of professional selfidentification of modern school students, with or without disabilities, is rather topical and significant.

Thus, during the investigation of motives for the choice of profession all the examinees - the high school students - have proven a tendency for external motives, such as the earnings, search of the prestige, fear of reproach, failure, as well as the influence on an individual by means of pressure, critics, reproach $-47,61 \%$.

$16,66 \%$ of the examinees have featured the tendency for the internal motives of the choice of profession, that is, the most significant criteria when choosing the profession for them shall be the social and personal significance; satisfaction with work because of its creative character; possibility of communication, leading of other people etc. Also, 35,71\% of the examinees of the two groups were characterized as individuals whose motives had been based of material stimulation, possibilities for career growth, approval by the collective, prestige, that is, the stimuli that would worth the individual's effort of an individual.

The results of the research of level of formation of readiness to choose the profession among the teenagers of the experimental and the control groups have also proven that in general the modern teenagers are not yet able to choose independently their future profession.

Thus, $31,25 \%$ of the examinees have featured the unreadiness to choose the profession, $52,08 \%$ - the low level of formation of such readiness.

Only the $4,16 \%$ of high-school students have featured the high level of readiness to choose the profession, with this they all consisted the control group.

$12,50 \%$ of the teenagers were characterized by the average level of readiness to choosing their profession.

Readiness to choose the profession implies the conscience by a teenage individual of their capacities, possibilities, interests and aims. However, most of the examinees of the experimental and the control groups would not be able to evaluate adequately their life plans and would not ponder about their living priorities and values.

The question of the specially elaborated questionnaire "Have you chosen your future profession?» was answered positively only by $18,75 \%$ of the disabled high school examinees, and upon concretization of this question it was discovered that most of them think of their future profession in the terms of the stereotype conceptions.

Results of the study of readiness of highschool students to choose their professional way by means of the methodics by A.P. Chernyavskaya (Table 1) has allowed making the following conclusions.

Modern high-school students in the system of inclusive education in general feature 
the low level of understanding of the integrity of their personality, the lack of willingness to realize their potential in practice, and the low level of thorough knowledge and skills in any sphere.

In general the high-school students of the experimental and the control groups have demonstrated the low level of formation of capacity to prognosticate their professional growth, and similarity of the professional preferences.

Most of the healthy students as well as the students with disabilities have been characterized by the dependency on parents, mode, prestige, friends, low level of apprehension of their "self", inability to take decisions independently when choosing the profession.

The same low indexes have been registered for the scale of the questionnaire «Level of information», despite the supposition that even the primary-level students would already have a large amount of information about the world of professions.

In the whole rather low indexes were registered for the scale «Decision taking» in both experimental and control groups, which may evidence the low level of professional selfidentification of the high-school students.

Table 1. Results of the study of level of formation of readiness to choose the profession in two groups of the examinees before the formative experiment

\begin{tabular}{lcccc}
\hline indexes & EG & CG & $t$ & $p$ \\
\hline Autonomy & $9,7 \pm 0,8$ & $9,8 \pm 0,9$ & 0,05 & $>0,05$ \\
Level of information & $10,0 \pm 1,1$ & $10,2 \pm 1,0$ & 0,52 & $>0,05$ \\
Decision taking & $8,8 \pm 0,8$ & $9,00 \pm 0,9$ & 0,34 & $>0,05$ \\
Planning & $6,7 \pm 0,6$ & $9,2 \pm 0,9$ & 2,23 & $<0,05$ \\
Emotional attitude & $14,3 \pm 1,4$ & $11,0 \pm 1,1$ & 1,85 & $>0,05$ \\
\hline
\end{tabular}

The evaluation of temporary perspective (the scale «Planning») has also been rather low. However, this scale has featured the positively significant differences between the indexes of the high-school students with disabilities and those with normal development. The students with disabilities have featured the more undeveloped capacity to form themselves the integral idea of their own lives, their past, present and future.

With this, according to the results of our study, the teenagers with disabilities in the conditions of inclusive education would be characterized by a rather developed necessity in choosing of the profession. It is remarkable that most of them would have the clear understanding that they would be realizing their potential precisely within the professional sphere.

The results of the study of peculiarities of intrapersonal relationship between the subjects of inclusive education

By means of the methodics «Semantic differential» there was defined the emotional and personal attitude of teenagers to their class-mate child who would have deviations in development. The results of such study allow us saying that the attitude of normal children to the children with peculiarities and deviations in their development have generally featured the emotional weakness (Table 2).

In the whole the most negative attitude was registered towards children with early children autism (ECA), as well as the hard-hearing children. A child with ECA would be perceived by many school-mates as «bad», «unpleasant», «undesirable» and at the same time as «useful», «important», and «necessary». On the contrary, children with infantile cerebral paralysis in most cases would be evaluated as «very mild», «good» and at the same time «unattractive» and «insignificant».

Thus, the results of the conducted research have proven that the education of a child with peculiarities and deviations in development in base levels of secondary schools would not provoke any special, highly negative emotions with the normally developing children.

The results of sociometric study (Table 3) evidence the expediency of organization of psychological assistance of inclusive educational process and professional orientation in particular. 
Table 2. Results of the study of emotional and evaluative attitude of normally developing teenagers towards their class-mates - children with peculiarities in development

\begin{tabular}{lccc}
\hline \multirow{2}{*}{ Categories of evaluation } & \multicolumn{3}{c}{ Average index within the group } \\
\cline { 2 - 4 } & 1 EG & $2 \mathrm{EG}$ & $3 \mathrm{EG}$ \\
\hline Good - bad & $-0,21 \pm 0,02$ & $1,22 \pm 0,02$ & $0,18 \pm 0,02$ \\
Unpleasant - pleasant & $-0,44 \pm 0,02$ & $1,02 \pm 0,03$ & $-0,12 \pm 0,01$ \\
Unattractive - attractive & $0,12 \pm 0,03$ & $-0,58 \pm 0,02$ & $0,38 \pm 0,02$ \\
Needless - necessary & $0,54 \pm 0,03$ & $0,37 \pm 0,02$ & $0,26 \pm 0,03$ \\
Useless - useful & $0,62 \pm 0,03$ & $0,38 \pm 0,02$ & $0,48 \pm 0,03$ \\
Undesirable - desirable & $-0,16 \pm 0,02$ & $0,25 \pm 0,02$ & $0,12 \pm 0,02$ \\
Unimportant - important & $0,24 \pm 0,03$ & $0,02 \pm 0,02$ & $0,16 \pm 0,01$ \\
Insignificant - significant & $0,02 \pm 0,01$ & $-0,42 \pm 0,03$ & $-0,36 \pm 0,02$ \\
Rude - mild & $-0,78 \pm 0,04$ & $0,82 \pm 0,03$ & $0,06 \pm 0,01$ \\
\hline
\end{tabular}

The major index of negative sociometric status has been registered in the first experimental group which included the children with early children autism. The number of negative choices by normally developing children towards their class-mates with ECA considerably exceeds the number of positive choices. With this the group was featured by the least index of emotional expansiveness which characterizes the capacity of a child to define the feeling of sympathy or antipathy towards other schoolmates. On the contrary, children with infantile cerebral paralysis and hard-hearing children have featured the expressed necessity in relationships with their agemates. Apart from ECA children, teenagers with other deviations feel their membership of a school collective. They long to build a certain relationship and therefore acquire the experience of communication and social behaviour.

It is remarkable that children with deviations in their development generally would not evaluate adequately their position in a school collective. In most cases they tend to underestimate their possibilities and significance for other members of the group. The cases when a teenager makes only the negative choices without any positive one may be considered as the action of a defensive mechanism. The sociometric study has also evidenced the mutual positive and negative choices in the second and third experimental groups, which prove the existing sympathies and antipathies, and friendly or hostile relationships with a special child in the integrated school collective.

Table 3. Results of sociometric study in the inclusive school collectives

Personal sociometric indexes

\begin{tabular}{|c|c|c|c|}
\hline \multirow[t]{2}{*}{ 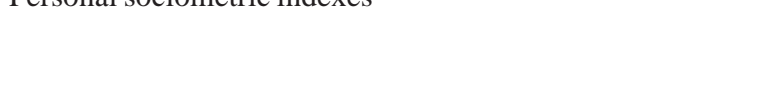 } & \multicolumn{3}{|c|}{ the groups } \\
\hline & $1 \mathrm{EG}$ & $2 \mathrm{EG}$ & $3 \mathrm{EG}$ \\
\hline Positive status in the group & $0,11 \pm 0,01$ & $0,18 \pm 0,02$ & $0,13 \pm 0,03$ \\
\hline Negative status in the group & $0,72 \pm 0,03$ & $0,34 \pm 0,03$ & $0,38 \pm 0,03$ \\
\hline Emotional expansivity & $0,04 \pm 0,01$ & $0,53 \pm 0,02$ & $0,48 \pm 0,02$ \\
\hline Adequacy of evaluation of one's own position in the group & $0,12 \pm 0,03$ & $0,16 \pm 0,01$ & $0,24 \pm 0,02$ \\
\hline
\end{tabular}

To estimate the attractiveness of a school collective for each of the participants of our study we have chosen the index of group solidarity by Seashore, adapted and modified according to our purposes. The attractiveness of a school collective has been highly evaluated by $26,66 \%$ of teenagers with ICP and 25,00\% of teenagers with hearing losses.

The results of the research of a group public opinion of the age-mates in connection with the personality of a child with deviations in development do not allow making any 
determinative conclusions about the existence of any tendency in the perception by teenagers of their class-mate that would be caused by his or her deviations.

Basing on the results of the study of peculiarities of relationships among the students of the integrated classes all integrated school collectives have been conditionally divided into two research groups: the experimental group in this case consisted of the ten school collectives where a child with peculiarities in development (or children, since some classes included two-three children with disabilities, and another classes only one child) has had the positive sociometric status and friendly relationships with most of his or her class-mates; the control group consisted of such integrated school collectives where the attitude of most class-mates has been characterized as unfriendly and hostile (10 classes). In the two contrast groups the empirical researches were aimed to reveal the psychological and social factors for formation of intrapersonal relationship between the normally developing teenagers and their class-mates with deviations from the norms of psycho-physical development.

The methodics of social and psychological self-attestation of the group as a collective (SPSA) has allowed defining the level of development of relations typical for a united collective within the group. Results of such investigation have evidenced the fact that the average indexes of integrated school collectives from the experimental group were featured by the higher indexes of all types of the collectivist relationships.

Positively significant differences in the two groups have been registered in connection with the scales «Solidarity» $(\mathrm{t}=2,88, \mathrm{p}<0,01)$ and «Level of contact» $(\mathrm{t}=2,84, \mathrm{p}<0,01)$. Within the experimental group most integrated school collectives have featured the solidarity of opinions in connection with the most important issues; in the most significant living experiences the teenagers of the experimental group generally tend to discuss the problems in conference more likely than the examinees of the control group.

During the examination of correlation between the expert estimation (the experts have been the teachers working in the integrated school collectives) and mutual estimation of the extent of expressiveness of personal qualities of the teenagers holding the leaders' positions and having a high sociometric status in the group, and the estimation of a «leader» by a child with disability, it was found out that the extent of expressiveness of such personal qualities as conflictivity $(\mathrm{t}=4,15$, $\mathrm{p}<0,001)$, mendacity $(\mathrm{t}=3,98, \mathrm{p}<0,001)$, aggressiveness $(t=4,43, p<0,001)$ has been considerably lower in the experimental group than in the control one.

Secondly, it should be noted that the correlation of estimation of level of expressiveness of qualities of a students' group leader has been rather adequate within the experimental group: teachers as well as the class-mates and the children with disabilities have coincided in their opinion when estimating of a «leader» $(p>0,05)$. It is worth reminding that children with deviations in development have estimated higher than normally developing children such qualities of their classmates holding the leader positions as discipline $(t=2,34, p<0,05)$ and level of organization $(t=2,64$, $\mathrm{p}<0,01$ ), which may evidence the aspiration of such teenagers to develop these qualities in themselves.

The control group have featured the nonaccordance of estimation of leaders' personality on behalf of the teachers and children with peculiarities in development with the estimations of another class-mates, thus, in particular, the positively significant differences were registered in the evaluation of the level of expression of such personal qualities as sociability $(t=5,97, \mathrm{p}<0,001)$, level of organization $(\mathrm{t}=3,43, \mathrm{p}<0,001)$ and justice $(\mathrm{t}=4,94, \mathrm{p}<0,001)$.

Results of the study of emotional barriers in intrapersonal communication of the teenagers of the two research groups have evidenced the fact that most of the teenagers of the experimental group $(56,06 \%)$ have featured the capability to concealing their emotions and expressing them adequately during the communication, whereas in the control group most of teenagers $(55,67 \%)$ have featured rather serious problems in establishing contacts with another people. Inability to manage and measure one's emotions, prevalence of negative emotions - to a large extent all this has been typical for the examinees of the control group.

Of great interest seem to be the results of investigation on the characteristic features of the examinees of the two research groups conducted 
through the personal questionnaire by Kettle (Table 4). There's been undertaken the comparative analysis of the results of research separately in connection with the leaders of inclusive school collectives, their members and the children with disabilities. It has been discovered that in the groups consisting of normal members of the inclusive school collectives the positively significant differences were registered only in the scales of «subordination - domination» $(\mathrm{t}=2,16$, $\mathrm{p}<0,05)$, and «conformism - nonconformism» $(t=3,07, p<0,01)$. Positively significant differences have been revealed in both leader group and the group of the teenagers with disabilities.

Table 4. Results of comparative analysis of characteristic profiles of the teenagers with deviations in development

\begin{tabular}{lcccc}
\hline Scales & EG & CG & $t$ & $\mathrm{p}$ \\
\hline Reserved disposition - sociability & $3,2 \pm 0,3$ & $5,7 \pm 0,5$ & 4,31 & $<0,001$ \\
Intelligence & $4,3 \pm 0,4$ & $4,8 \pm 0,4$ & 0,89 & $>0,05$ \\
Emotional inestability & $5,6 \pm 0,5$ & $7,8 \pm 0,6$ & 2,82 & $<0,05$ \\
Subordination - domination & $4,8 \pm 0,5$ & $4,5 \pm 0,4$ & 0,52 & $>0,05$ \\
Restraint - expressiveness & $6,2 \pm 0,6$ & $5,6 \pm 0,5$ & 0,77 & $>0,05$ \\
Behaviorial normativity & $4.4 \pm 0,4$ & $4,8 \pm 0,5$ & 0,63 & $>0,05$ \\
Shyness - braveness & $4,7 \pm 0,4$ & $5,1 \pm 0,5$ & 0,63 & $>0,05$ \\
Toughness - sensibility & $3,8 \pm 0,4$ & $4,3 \pm 0,5$ & 0,78 & $>0,05$ \\
Trust-suspiciousness & $7,9 \pm 0,8$ & $4,8 \pm 0,5$ & 3,30 & $<0,01$ \\
Practicism-imagination & $5,1 \pm 0,5$ & $5,2 \pm 0,5$ & 0,07 & $>0,05$ \\
Straightforwardness-diplomacy & $4,9 \pm 0,5$ & $4,7 \pm 0,4$ & 0,02 & $>0,05$ \\
Self-confidence-anxiety & $5,4 \pm 0,5$ & $7,3 \pm 0,7$ & 2,21 & $<0,05$ \\
Conservatism-radicalism & $3,7 \pm 0,4$ & $3,8 \pm 0,4$ & 0,02 & $>0,05$ \\
Conformism-nonconformism & $3,9 \pm 0,4$ & $4,1 \pm 0,4$ & 0,06 & $>0,05$ \\
High and low self-control & $5,0 \pm 0,5$ & $4,6 \pm 0,5$ & 0,80 & $>0,05$ \\
Relax-tension & $6,4 \pm 0,6$ & $3,1 \pm 0,3$ & 4,93 & $<0,001$ \\
Adequacy of self-estimation & $5,9 \pm 0,6$ & $3,3 \pm 0,3$ & 3,88 & $<0,001$ \\
\hline
\end{tabular}

The teenagers with disabilities of the experimental group have been more sociable $(\mathrm{t}=4,31, \mathrm{p}<0,001)$, emotional stable $(\mathrm{t}=2,82, \mathrm{p}<0,001)$, relaxed ( $\mathrm{t}=4,93, \mathrm{p}<0,001)$, less anxious $(\mathrm{t}=2,21$, $\mathrm{p}<0,05)$ and suspicious $(\mathrm{t}=3,30, \mathrm{p}<0,01)$. The same significant differences have been obtained in the leader groups, however, these differences were registered for the scales «toughness - sensibility» $(\mathrm{t}=4,67, \mathrm{p}<0,001)$, behaviourial normativity $(\mathrm{t}=5,34$, $\mathrm{p}<0,001)$ and straightforwardness $(\mathrm{t}=3,56, \mathrm{p}<0,001)$.

Results of the research of peculiarities of relationships of inclusive schools with the students' families

The next step of our study has been the investigation of the peculiarities of cooperation of school and family in the context of integrated education. It has been found out that most teachers in the control group have featured the higher level of aggressivity $(t=2,33, p<0,05)$, and low level of development of empathy tendencies $(t=2,65$, $\mathrm{p}<0,05)$. Besides, during the investigation of the positions of teachers in cooperation with the parents of the students it was noted that the teachers of the experimental group have been more disposed to the activating position $(t=4,10, p<0,001)$ and less - in comparison with the teachers of the control group - disposed to the formally informative position $(t=2,54, p<0,05)$ in their interaction with the parents of the students.

Tthe parents from the experimental group have generally experimented the feelings of interest $(5,1 \pm 0,5)$ and satisfaction $(4,7 \pm 0,5)$ from communication with the teachers, whereas in the control group negative emotions have been prevailing: anxiety $(8,2 \pm 0,7)$, indignation $(7,7 \pm$ $0,7)$, tension $(6,7 \pm 0,7)$, tiredness $(6,3 \pm 0,6)$.

Results of the investigation of the parents' attitude towards the teachers of their children, both normal and with deviations in development, have evidenced the fact that despite the cognitive acceptance of a teacher and his or her estimation as a rather illustrated person, the effective and 
interactive components of the relationship implying the attitude towards the personality of a teacher and the real direct contact, positively differ in the two research groups, which witnesses the dysfunction of the relationship between the school and the family in the control group, and, therefore, the determinism of the intrapersonal cooperation in the integrated school collective by the social and psychological characteristics and the type of the position of a teacher in such cooperation.

Moreover, the investigation of the parents' attitude in the families of experimental and control groups has revealed that the experimental group features to the less extent than the control one such attitudes as non-acceptance of their child with deviations in psychophysical development $(t=5,19, p<0,001)$, and his or her emotional rejection combined with the dominating hyper-protection $(t=4,77, p<0,001)$ or emotional rejection together with hyper-protection $(\mathrm{t}=5,91, \mathrm{p}<0,001)$.

\section{DISCUSSION}

Results of the first series of the empirical study has evidenced that the necessity and some vague idea of professions, following the stereotypes, dependency in making a choice, lack of autonomy and resolution, inadequate dreams about one's profession and the future life - all these characteristics would be typical for highschool students with disabilities who feature the inappropriate for their age childishness and the high level of infantilism. In most cases they are not aware of the world of professions and the list of requirements to an individual, of the list of necessary knowledge and skills to acquire a certain profession.

Results of the second series of this empirical study allows the conclusion that the dominating role in the intrapersonal interaction of subjects of the inclusive education would belong to the personality of the teacher, and his or her professional and personal characteristics, as well as his or her position in the interaction with other subjects.

The heightened aggressivity of a teacher, frustration, tendency to the depressive state of mind combined with the formally informative position during the interaction with the parents of the students, would be connected with the establishing of the unfavorable psychological climate in the students' collective as well as of the dysfunctional relationship in the system «teacher - parent», whereas the activating position of a teacher during the interaction with the subject of the inclusive education would ensure achievement of the positive effect. Zombying and manipulative positions of a teacher in combination with a negative idea of the inclusive education and with the heightened aggressivity and intolerance as personal characteristics would cause the conflictive relationship in all subsystems of intrapersonal interaction of the subjects of inclusive education.

\section{Findings}

Thus, the results of the empirical study evidence the strongly pronounced necessity in a special effort for activization of the professional self-identification of high-school students with disabilities in the conditions of the inclusive education. With this the professional orientation work should be aimed to develop the subjectiveness of the students with disabilities as the factor of their personal and professional selfidentification.

Besides, the successful actualization of the professional self-identification of the teenagers with disabilities implies the creation in the inclusive schools of the inclusive environment where all subjects of the inclusive education would cooperate harmonically.

The basic conditions for actualization of the professional self-identity of the teenagers with disabilities in the conditions of the inclusive education would be the elaboration of purposeful programs of psychological assistance aimed to the development of the subjectiveness in school students with disabilities and to the harmonization of the inclusive environment in a school, optimization of relationships between all subjects of the inclusive education.

\section{REFERENCES}

1. Andreeva, L.V., Pedagogical conditions for integration of children with the development problems into a general education school. Materials of the international seminar «Integrated education: problems and perspectives. - SPb.: Peter, 1996.

2. Astakhov, V.M., Functional approach to the investigation of the state of anxiety. Applied 
psychology, 1999; 1: 41-47

3. Bonkalo, T.I., Social and psychological paternalism in school and family: theory, methodology, practice: monography. - Kolomna: 2011,

4. Bonkalo, T.I. \& Tsigankova, M.N., Peculiarities of the professional self-identification of highschool students with disabilities in the conditions of the inclusive education. Scientific notes of Russian State Social University,2015; 1: 12-20.

5. Ekzhanova E.V. \& Reznikova, E.V., The basis of integrated education: manual for higher education instututes. - M.: Drofa, 2008.

6. Konopleva, A.N. \& Leschinskaya, T.L., Integrated education of children with the peculiarities of psychophysical development. Monography. - M. : NIO, 2003.

7. Kon, I.S., Psychology of the youth period. M., 1999; 145-155

8. Kotova, S., Manual for inclusivity: providing access to education for all. - Vladimir: TransitIKS, 2009.

9. Lebedinskaya, K.S. \& O.S. Nikolskaya, Diagnosis of the early children autism: initial signs: manual. - M.: Prosveschenie, 1991.

10. Malofeev, N.N., Occidental experience of assistance to the students with the special needs in the conditions of the integrated education (by the materials of the Report of the European agency for developing of special education). Defectology, 2005; 5: 3-18

11. Priazhnikov, N.S., Personal and professional self- identification. - M, 1996.

12. Rozhkov, M.I., Bajborodova, L.V. \& Kovalchuk, M.A., Education of tolerance among the school students. Yaroslavl, 2003.

13. Russian statistics annual. Statistics collection. M: Federal Service for State Statistics, 2011

14. Shapovalenko, I.V., Psychology of development and age psychology. - M.: Uright, 2012.

15. Staroverova, M.S., Inclusive education. A handbook of a pedagogue working with children with disabilities: methodical manual / M.S. Staroverova [and others]; edited by M.S. Staroverova. - M.: Vlados, 2011.

16. The Law of the city of Moscow «About the education of persons with disabilities in the city of Moscow», 16 of $28^{\text {th }}$ of April, 2010

17. Tolstova, V. A. \& Arlanova, L.D., School program for working with family. Head of studies in elementary school, 2007; 8: 4 -11.

18. Ufimtseva, L.P., Psychological problems of integrated education of children with hearing losses in the secondary school. Education of children with deviations in development, 2005; 6: 65-70.

19. Zajtseva, G. L., Dialogue with Vigotsky L.S. about the problems of the contemporary deafand-dumb pedagogy. Defectology, 1998; 2: 34 43

20. Ilina I.Yu., Kryukova E.M., Zotova A.I., Chardymskiy M.G., Skudareva N.Z., Scientific Degrees As A Status Characteristic Of Russian University Teachers. International Education Studies. 2015; 8(5): 165-172. 